\title{
COMPARTILHANDO SABERES EM GEOMETRIA: INVESTIGANDO E APRENDENDO COM NOSSOS ALUNOS
}

\author{
Regina Célia Grando* \\ Adair Mendes Nacarato** \\ Luci Mara Gotardo Gonçalves ${ }^{* * *}$
}

\begin{abstract}
RESUMO: O presente artigo tem como objetivo discutir as atuais tendências didático-pedagógicas para o ensino de geometria na educação básica, tomando como foco o trabalho que vem sendo desenvolvido por um grupo de estudos e pesquisas sobre esse campo de saber, na Universidade São Francisco (Itatiba, SP). Para esta discussão selecionamos uma tarefa exploratório-investigativa envolvendo os conceitos de área e perímetro do quadrado, elaborada de modo colaborativo no grupo e aplicada por alguns de seus participantes em suas respectivas salas de aula. Destacamos uma dessas experiências, realizada numa turma de $7^{\mathrm{a}}$ série, sob responsabilidade da professora de matemática Luci Mara, participante do grupo e co-autora deste artigo. A análise compartilhada desta experiência no grupo evidenciou a importância de considerar como válidas as diferentes formas que os alunos encontram para registrar e argumentar sobre suas estratégias, hipóteses e conclusões.
\end{abstract}

Palavras-chave: Ensino de geometria. Tarefas exploratório-investigativas. Argumentaçóes e provas.

* Doutora em Educação e professora do Programa de Pós-Graduação em Educação da Universidade São Francisco (USF). E-mail: regina.grando@saofrancisco.edu.br

** Doutora em Educação e professora do Programa de Pós-Graduação em Educação da USF. E-mail: adamn@terra.com.br

*** Professora da Rede Municipal de Ensino de Itatiba (sp).E-mail: dosgonçalves@uol.com.br

Cad. Cedes, Campinas, vol. 28, n. 74, p. 39-56, jan./abr. 2008

Disponível em <http://www.cedes.unicamp.br> 


\title{
SHARING KNOWLEDGEMENT IN GEOMETRY: INVESTIGATING AND LEARNING WITH OUR STUDENTS
}

\begin{abstract}
This article aims at analyzing the present didactic and pedagogical trends for geometry teaching in elementary education, focusing on the work being developed by a study and research group on this knowledge field, at Universidade de São Francisco, a university in Itatiba, São Paulo. For this analysis, an exploring and investigatory task was selected. It involves the concepts of area and perimeter in a square. The task was developed cooperatively by the group and applied by some of its members, in their classrooms. We took a closer look at one of these experiences, carried out in a class of $7^{\text {th }}$ graders from elementary school, under the responsibility of mathematics teacher Luci Mara, a member of the group and one of the authors of this article. The shared analysis of this experience in the group has highlighted the importance of considering the students' different ways of recording and discussing about their strategies, hypotheses and conclusions.
\end{abstract}

Key words: Geometry teaching. Exploratory and investigatory tasks. Discussion and proofs.

\section{Introdução}

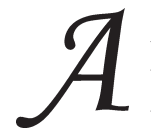

nossa experiência como docentes e formadoras de professores tem-nos revelado que, apesar de tantas pesquisas e discussóes teóricas, a geometria ainda está ausente da maioria das salas de aula. Geralmente os alunos chegam ao ensino superior com pouco ou nenhum conhecimento básico de geometria.

Visando criar um espaço alternativo de formação docente, principalmente para os alunos do curso de licenciatura em Matemática, constituímos, em 2003, um grupo de estudos e pesquisas sobre o ensino de geometria. Além dos graduandos, o grupo é formado também por professores da educação básica e alunos da pós-graduação. Existe certa rotatividade quanto aos alunos. A cada semestre e, principalmente, no início de cada ano letivo ocorrem saídas de graduandos e ingressos de outros. No entanto, temos nos mantido numa faixa de 15 participantes por semestre. Há quatro professores escolares que fazem parte do grupo desde 2003 e outras duas ingressaram em 2005. Consideramos importante ressaltar que tanto professores quanto alunos 
participam do grupo com o objetivo de buscar sua formação e novas aprendizagens e não existe pressão quanto ao cumprimento de programas, visto que as tarefas são organizadas a partir das necessidades e ritmo de trabalho dos seus participantes, nem limitações de tempo para concluí-las durante os encontros - assim como ocorre em uma sala de aula -, o que possibilita um contexto bastante interessante e produtivo.

O grupo se reúne semanalmente, por um período de duas horas, das 17 às 19 horas. Em 2005, nossos encontros ocorreram às segundas-feiras. Nosso objetivo é produzir, de forma colaborativa, propostas alternativas para serem trabalhadas em sala de aula.

A cada semestre elegemos uma temática de geometria para estudo e, a partir dela, estudamos e elaboramos situaçôes para a sala de aula. Essas situações são aplicadas pelos professores, contando com a colaboração dos alunos da graduação e da pós-graduação. Após a aplicação, os registros dos alunos e dos responsáveis pela atividade são trazidos para o grupo, discutidos e analisados, gerando a produção de conhecimentos em geometria.

Essa dinâmica vem possibilitando que o grupo adquira uma dimensão colaborativa - quer pelos subgrupos formados por professores da educação básica e alunos da graduação e pós-graduação, quer pela equipe de formadoras que vem sistematizando e teorizando sobre essas experiências (Nacarato et al., 2005). Uma das características marcantes no grupo é o respeito ao outro, a sua forma de pensar e buscar alternativas para as situaçôes propostas. O aluno e o professor têm voz e são ouvidos.

Por essa dimensão colaborativa, a partir de agosto de 2005, o grupo passou a se denominar GRUCOGEO (Grupo Colaborativo em Geometria).

Desde 2004, elegemos como temática de trabalho as tarefas exploratório-investigativas em geometria. Temos lido, discutido e realizado, no grupo, tarefas dessa natureza. Num primeiro momento, em 2004, tomamos alguns materiais já publicados e trabalhamos a partir deles, selecionando e aplicando as tarefas já elaboradas. Em 2005, partimos para a elaboração de nossas próprias tarefas. Para isso, em subgrupos, temos elaborado tarefas que são submetidas à discussão do grupo. Nessa etapa, a tarefa é analisada com vistas à discussão de suas potencialidades e possibilidades de tornar-se uma tarefa investigativa ou manter-se no nível da exploração e, geralmente, passa por ajustes e 
modificações de redação em seu texto. Após esse processo, a tarefa é aplicada em sala de aula e seus resultados são discutidos e analisados posteriormente no grupo.

No presente artigo trazemos a análise de uma dessas experiências. O objetivo é discutir as potencialidades de tarefas exploratório-investigativas em geometria, no que diz respeito aos processos de argumentação.

As argumentações em geometria nas tarefas exploratório-investigativas

Muito se tem discutido e pesquisado sobre o ensino de geometria na educação básica. Pode-se dizer que esse ensino, até a década de 1960, esteve pautado por um excesso de formalismo, com a prevalência das demonstrações geométricas euclidianas. $\mathrm{O}$ caráter estritamente formal e axiomático da matemática produzida pelos matemáticos profissionais estabelecia os critérios de verdade dessa área do conhecimento. Não se questionavam esses critérios quanto à matemática escolar. Assim, outros processos de argumentação em geometria não encontravam espaços na escola.

O formalismo da matemática acentuou-se nas décadas de 1960 e 1970, durante o Movimento da Matemática Moderna, e a geometria, ao revestir-se de uma concepção voltada à linguagem, ficou relegada a um segundo plano nos currículos e livros didáticos brasileiros. Isso acabou por gerar o seu abandono pela escola básica, como evidenciamos em inúmeras pesquisas na área de Educação Matemática, principalmente na década de 1980 .

Essas denúncias de abandono acabaram por mobilizar a comunidade de educadores matemáticos a buscar, inicialmente, alternativas para o ensino de geometria com exemplos de atividades e uso de materiais manipuláveis, numa visão bastante empirista, tal como identificada na pesquisa de Andrade (2004). No entanto, o levantamento realizado por esse autor revela que houve uma mudança de tendência didático-pedagógica na década de 1990. Por tendência didático-pedagógica em geometria entendemos como "o modo de produzir conhecimentos geométricos na sala de aula e para a sala de aula" (Andrade \& Nacarato, 2004, p. 61).

As pesquisas e produções brasileiras revelam que a geometria vem assumindo um caráter mais exploratório e investigativo, buscando subsídios teóricos em outras áreas do conhecimento, como a epistemologia, a 
história, a psicologia sociocultural e a linguagem. Emergem, assim, novas formas de conceber e produzir conhecimentos geométricos em sala de aula, principalmente com dinâmicas de maior dialogicidade entre professor e aluno, numa perspectiva de negociação e produção de significados. Nesse contexto, buscam-se ressignificações para os processos de validação e verdade em Matemática.

Garnica (2002) considera que a Educação Matemática, enquanto uma prática social, não se pode valer única e exclusivamente dos critérios de validação e verdade postulados pelos matemáticos profissionais. Há que se repensar o que poderia ser considerado como verdade numa sala de aula de matemática da educação básica.

Uma proposta mais geral, no entanto, é o fortalecimento da concepção de que a matemática profissional - ou matemática acadêmica - é uma dentre as várias matemáticas existentes, uma dentre as várias formas de apreensão do mundo, uma dentre as etnomatemáticas. A partir daí, as classificações das formas de argumentação poderiam ser revistas (...). O estudo das argumentaçōes sobre conteúdos matemáticos pode ser visto sob diferentes perspectivas. Para tanto, torna-se necessário falarmos em diferentes formas de argumentação, ou de modos diferenciados - mas coexistentes nas salas de aula - para o estabelecimento de justificaçôes (...). Dirige-se mais à prática profissional e científica de justificação de conhecimento matemático, devendo ser relativizada e mais estudada quanto a sua forma de utilização em salas de aula. (Garnica, 2002, p. 97)

As tarefas exploratório-investigativas mostram-se altamente potencializadoras de processos de argumentações e provas em geometria na sala de aula. Elas podem ser realizadas a partir de uma tarefa ou um conjunto de tarefas no qual o aluno passa a identificar qual é o problema a resolver e como resolvê-lo. Trata-se de problemas abertos que possibilitam diferentes perguntas, estratégias de resolução e processos de validação.

Concordamos com Ponte (2003), que pontua que a priori não há como avaliar se uma tarefa se constituirá ou não em uma tarefa investigativa, pois isso depende do seu grau de dificuldade, do grupo de alunos e do tempo dedicado a sua realização. Diante de um problema e/ou tarefa aberta, o aluno elabora conjecturas, testa-as e busca processos de validação.

As argumentações são geradas no momento de negociação e validação (convencimento) de estratégias. 
Com a argumentação não se pretende demonstrar a verdade de uma afirmação, nem mostrar a validade lógica de um raciocínio, mas obter a concordância de outrem para a validade de uma dada afirmação. O objetivo da argumentação seria o de obter a concordância do interlocutor, convencer, enquanto que o da demonstração seria o de garantir a verdade. No entanto, nem sempre os argumentos que convencem são válidos. $\mathrm{Na}$ argumentação, quaisquer meios, em princípio, são lícitos. (...) Como resultado da argumentação, as soluções dos problemas não têm caráter definitivo. (Fernandes \& Fonseca, 2004, p. 249)

Com relação ao ensino de geometria pautado em uma perspectiva de tarefas exploratório-investigativas, podemos afirmar que estas se vêm mostrando favoráveis para minimizar algumas das "lacunas" existentes em decorrência do pouco ensino de conteúdos geométricos na educação básica. Como são tarefas abertas, o conhecimento geométrico exigido, inicialmente, é restrito ao conteúdo de que trata a tarefa. Se o aluno tiver um domínio restrito dos conteúdos geométricos, muito provavelmente a tarefa venha a ficar no nível da exploração, mas, caso seja um aluno que apresente um domínio maior dos conteúdos geométricos e mesmo algébricos, existe grande possibilidade de que a tarefa se torne, para ele, investigativa. Abrantes (1999, p. 155) aponta essa particularidade nas investigações geométricas:

Fazendo apelo à intuição e à visualização e recorrendo, com naturalidade, à manipulação de materiais, a geometria torna-se, talvez mais do que qualquer outro domínio da Matemática, especialmente propícia a um ensino fortemente baseado na realização de descobertas e na resolução de problemas, desde os níveis escolares mais elementares. Na geometria, há um imenso campo para a escolha de tarefas de natureza exploratória e investigativa, que podem ser desenvolvidas na sala de aula, sem necessidade de um grande número de pré-requisitos e evitando, sem grande dificuldade, uma visão da Matemática centrada na execução de algoritmos e em "receitas" para resolver problemas-tipo.

É importante destacar que, mesmo que a tarefa seja resolvida como uma simples exploração, sem tornar-se investigação, muitos conteúdos matemáticos e, nesse caso, geométricos podem ser mobilizados ou mesmo desenvolvidos durante o trabalho. Segundo Ponte, Brocardo e Oliveira (2003, p. 71), as investigações em geometria também podem

(...) contribuir para concretizar a relação entre as situações da realidade e situações matemáticas, desenvolver capacidades, tais como a visualização 
espacial e uso de diferentes formas de representação, evidenciar conexões matemáticas e ilustrar aspectos interessantes da história e da evolução da Matemática.

Em razão das vantagens e possibilidades de trabalho com as tarefas exploratório-investigativas, estas foram adotadas não apenas como temática, mas também como metodologia de trabalho do GRUCOGEO, desde 2004, quando nos limitamos a explorar tarefas já produzidas por outros grupos e presentes na literatura.

A tarefa exploratório-investigativa: relato de uma experiência

No primeiro semestre de 2005 o grupo assumiu como foco de trabalho a produção de tarefas exploratório-investigativas em geometria. Após a realização de algumas delas, extraídas de materiais já publicados, decidimos que o próprio grupo elaboraria outras, com vistas à aplicação em salas de aula da educação básica e posterior apresentação, discussão e análise no grupo.

Uma das tarefas, elaborada pela graduanda do primeiro semestre do curso de Matemática, Carina Silva Barros, foi apresentada ao grupo, discutida e passou a ter a seguinte redação:

Abaixo tem-se um quadrado. Este quadrado tem $4 \mathrm{u}$ de lado. Assim

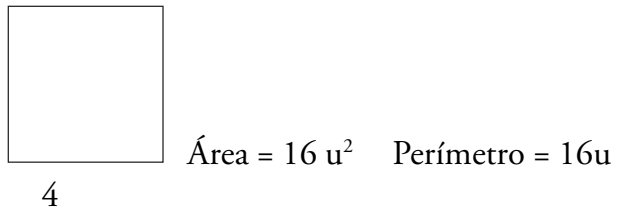

Essa igualdade é válida apenas para este quadrado?

Investigue e escreva suas conclusōes.

Nas semanas seguintes, os professores do grupo, individualmente ou em parcerias com alunos da graduação, aplicaram essa tarefa em suas respectivas salas de aula e trouxeram para o grupo o material produzido pelos alunos, bem como algumas discussões ocorridas no momento da socialização em suas respectivas salas de aula. 
Selecionamos para este artigo a experiência da professora de Matemática Luci Mara, realizada numa $7^{\text {a }}$ série de uma escola municipal de Itatiba (SP) na qual atua. Apresentaremos os relatos da aula feitos pela Luci Mara, bem como os registros de alguns alunos da classe e as discussóes ocorridas no grupo.

Luci Mara já havia sido a professora da turma na qual a tarefa foi aplicada $\left(7^{\mathrm{a}} \mathrm{D}\right)$ e, portanto, tinha conhecimento de que aquela seria a primeira tarefa exploratório-investigativa que esses alunos fariam. Foi solicitado que realizassem o registro no papel e - aproveitando o retroprojetor que era novo na escola - também o fizessem, para a socialização, em sacos plásticos (material disponibilizado aos alunos em substituição à transparência). $\mathrm{O}$ trabalho foi realizado em grupos de quatro alunos, dos quais dois ficaram responsáveis pelo registro: o do papel e o do saco plástico.

A professora notou que, nos registros no papel, a maioria dos alunos sentiu necessidade de fazer o desenho, colando papel quadriculado para representar a área; outros fizeram o desenho e quadricularam o quadrado com régua.

Nos registros em sacos plásticos os alunos procuraram sintetizar o registro escrito e o relator apresentou a conclusão do grupo. No momento da socialização dessa tarefa, junto ao GRUCOGEO, esses sacos plásticos foram apresentados pela professora Luci Mara. Essa iniciativa foi motivo de discussão no nosso grupo. Destacamos o quanto essa atitude foi um elemento de motivação para a produção dos registros coletivos. Primeiro, pelo fato de o retroprojetor ser um instrumento novo na escola e, portanto, objeto de curiosidade dos alunos; segundo, a possibilidade de se ter um leitor para as produções escritas, tornando o registro significativo para o grupo de alunos que o produziu, para a classe como um todo, para a professora e para o próprio GRUCOGEO, que pôde analisar as estratégias e argumentações dos alunos, em um contexto de sala de aula. Nesse sentido, Smole e Diniz (2001, p. 32) destacam a importância de haver um destinatário para as produçôes dos alunos:

É preciso que os textos elaborados não sirvam apenas para os alunos mostrarem que sabem ou não escrever. É preciso que a escrita seja trabalhada na escola tal como existe na sociedade e não se configure em um exercício mecânico e artificial, desprovido de sentido. Assim, a produção dos textos nas aulas de matemática deve ter sempre um destinatário, o qual pode ser outra pessoa, ou mesmo quem escreveu o texto quando este foi elaborado para não 
esquecer algo ou para organizar algum tema estudado. Conhecido ou desconhecido, é preciso que haja um leitor em potencial dos escritos que serão produzidos.

Essa motivação para a produção do registro foi evidenciada, inclusive, pela Luci Mara, quando relata que um dos grupos de sua turma, cujos alunos se mostravam pouco interessados pelas atividades escolares, a surpreendeu. Ela achava que eles não iriam fazer nada; entretanto, eles chegaram às seguintes conclusões:

- Só vale para o 4 .

- Menor que 4, a área é menor que o perímetro.

- Maior que 4, a área é maior que o perímetro. idéias:

No registro escrito, o grupo apresentou a seguinte seqüência de

\section{Figura 1}

Registro de um dos grupos

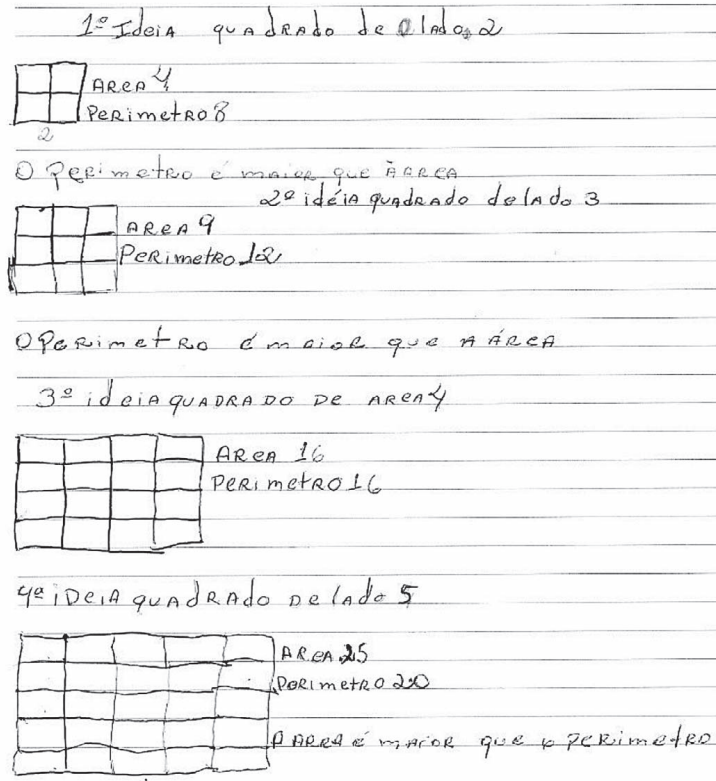

Cad. Cedes, Campinas, vol. 28, n. 74, p. 39-56, jan./abr. 2008 


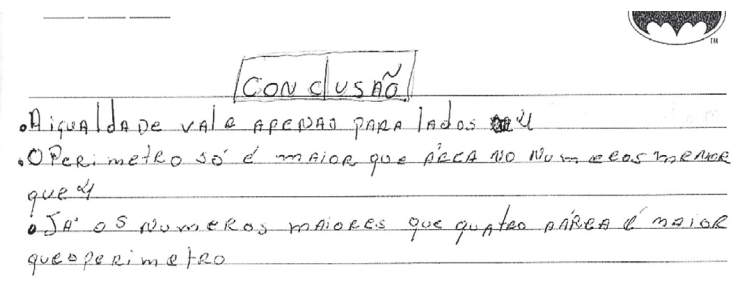

Chamam-nos a atenção, nesse registro, os desenhos feitos pelos alunos, como forma de comunicação de suas idéias. Embora eles não representem o quadrado, os alunos os quadricularam, garantindo o conceito de área. Para chegar a uma generalização, partiram de quatro casos: dois quadrados cujos lados medem menos que $4 \mathrm{u}$ (lados com $2 \mathrm{u}$ e $3 \mathrm{u}$ ), o quadrado de lado $4 \mathrm{u}$ e um quadrado de lado maior que $4 \mathrm{u}$ (lado com $5 \mathrm{u})$. Para eles, esses casos já foram suficientes para o estabelecimento de uma conclusão.

Em outro grupo, notamos o empenho em detalhar as argumentações de cada uma das idéias surgidas na discussão. Transcrevemos esse registro:

Sim, é válida apenas para esse quadrado.

$1^{\text {a }}$ idéia: porque um quadrado tem quatro lados, por isso se ele tem $4 \mathrm{u}$ de lado a soma dos lados resulta em 16 e a área também será 16 , porque $4 \times 4=16$.

$2^{a}$ idéia: se cada lado do quadrado mede 5 e o perímetro é a soma dos lados, conseqüentemente o resultado do perímetro será 20 , já a área é a multiplicação do comprimento com a largura, então, é só multiplicar 5 x 5 e o resultado da área será 25. Obs: o perímetro foi menor que a área. [Ao lado desta resposta colaram o quadrado de papel quadriculado]

$3^{\mathrm{a}}$ idéia: fizemos o mesmo que na idéia anterior. Só que com um número diferente (o 3). O resultado foi o seguinte: $\mathrm{P}=12$ e $A=9$. Obs: o $P$ foi menor que A. [Aqui também, ao lado desta resposta colaram o quadrado de papel quadriculado]

Conclusão: quando a medida dos lados é maior que quatro, o P é menor que a área e quando a medida dos lados é menor que 4 , o $\mathrm{P}$ é maior que a área.

Para esse grupo apenas três casos (um com o quadrado de lado $4 \mathrm{u}$, outro quadrado de lado $5 \mathrm{u}$ e outro de lado $3 \mathrm{u}$ ) foram suficientes para a conclusão. Teriam esses alunos utilizado outros quadrados? $\mathrm{Ou}$ foi uma questão intuitiva? 
Outro aspecto que diferencia esse registro do anterior diz respeito, por um lado, ao nível de detalhe nas argumentaçōes e, por outro, ao fato de recorrerem à representação do quadrado com papel quadriculado, também garantindo o conceito de área. Quanto ao detalhamento, entendemos que o fato da professora ter anunciado aos alunos que esses registros seriam motivo de análise e discussão no grupo dos "professores da universidade" (expressão que vem sendo utilizada pelos alunos e professores da rede pública para se referirem ao GRUCOGEO) reforça o pressuposto discutido anteriormente sobre a importância de um leitor para as produções dos alunos.

Um terceiro registro, produzido num grupo só de meninas, que nos chamou a atenção tinha as seguintes estratégias:

- Iniciaram fazendo o desenho de um quadrado qualquer e o quadricularam, indicando que era o quadrado de $4 \mathrm{u}$ de lado, obtendo área $16 \mathrm{u}^{2}$ e perímetro $16 \mathrm{u}$;

- mantendo o mesmo tipo de raciocínio, procuraram fazer um quadrado de área e perímetro igual a 2. Anotaram em seu registro: " $2^{a}$ idéia: fazer um quadrado de 2 de área e 2 de perímetro, mas não deu certo". Logo abaixo dessa afirmação há o desenho de um quadrado de lado 2 u que foi quadriculado mostrando as 4 unidades de área e registraram: $\mathrm{P}=8 \quad \mathrm{~A}=4$. $\mathrm{E}$ concluíram que "o perímetro é o dobro da área";

- registraram uma terceira idéia: "Fazer quadrado com números naturais, também não dá certo";

- finalmente, abandonaram o recurso do registro por desenho e elaboraram a seguinte tabela:

\begin{tabular}{|l|c|c|c|c|c|c|c|c|c|}
\hline Lado & 1 & 2 & 3 & 5 & 6 & 7 & 8 & 9 & 10 \\
\hline Perímetro & 4 & 8 & 12 & 20 & 24 & 28 & 32 & 36 & 40 \\
\hline Área & 1 & 4 & 9 & 25 & 36 & 49 & 64 & 81 & 100 \\
\hline
\end{tabular}

Logo abaixo da tabela, registraram a seguinte conclusão: "Quando o lado do quadrado medir 1, 2 e 3, o perímetro é maior do que a área, quando o lado do quadrado for maior do que 4, a área é maior”. 
Esse registro, quando compartilhado no GRUCOGEO, possibilitou algumas inferências quanto ao movimento das idéias: inicialmente as alunas tiveram necessidade do desenho do quadrado para a visualização - apesar de ele ter sido apresentado na tarefa -, mas elas o quadricularam, evidenciando a apropriação do conceito de área; para a segunda idéia, provavelmente, as alunas estavam conjecturando que, para qualquer número natural, fosse possível construir um quadrado com área e perímetro de mesmo valor. Daí a afirmação de que "não dá certo". A elaboração da tabela possibilitou a organização dos dados, variando o valor do lado, atribuindo três medidas menores do que 4 e seis maiores do que 4. Com esses valores, já sentiram segurança para concluir que o único quadrado em que as medidas do perímetro e área são representadas por um mesmo valor é o de lado $4 \mathrm{u}$.

Interessante observar que em nenhum grupo da classe houve a atribuição de valores não-naturais para a medida do lado do quadrado. Seria isso decorrente do conceito de área - pela visualização dos quadriculados - que estava muito presente nas estratégias desses alunos? Segundo a professora Luci Mara, ninguém tentou fazer a tarefa sem ser com números naturais, pois o papel quadriculado induz a um trabalho com números naturais.

Um quarto e último registro que selecionamos para discussão foi o do único grupo da turma que buscou uma generalização da tarefa, ou seja, para esse grupo a tarefa de fato se tornou investigativa. Segundo a professora, esse foi um outro grupo da classe que a surpreendeu. Nele há um aluno (aqui denominado Rô) que veio de uma escola particular e que apresenta dificuldades de relacionamento com os colegas. Ele participa do "grupo de estudos" que existe na escola fora do horário de aulas, em que os alunos se reúnem para estudar. Para a presente tarefa, ele apresentou uma resolução algébrica (detalhe: eles ainda não tinham estudado fatoração e equação de $2^{\circ}$ grau). Para o registro das estratégias, lembrou-se da matéria que viu no caderno do seu primo e deu a seguinte resposta:

$$
\begin{aligned}
& \text { 1a idéia: } \\
& P=4 \ell \\
& A=\ell^{2}
\end{aligned}
$$

Para que $4 \ell$ seja igual a $\ell^{2}, 4 \cdot 4=4^{2}$ 
$16=16$

$2^{a}$ idéia:

$\ell^{2}=4 \ell$

$\ell^{2}-4 \ell=0$

$\ell(\ell-4)=0$

$\ell=0$ ou $\ell=4$, como não existe um quadrado com lado $=0$, então $\ell=4$.

A resolução desse aluno foi bastante significativa para ele próprio, que, ao apresentá-la para a classe, surpreendeu não apenas os colegas, como a própria professora. Sem dúvida, Rô foi valorizado pelos colegas do grupo de trabalho, que não apenas aceitaram sua resolução como o escolheram para ser o relator do grupo. Essa atitude, com certeza, foi importante para melhorar a auto-imagem de Rô na classe.

A professora Luci Mara contou que, após a realização e socialização dessa tarefa, a sala tem estado mais empenhada e os alunos mais motivados, lendo antecipadamente o livro didático para as aulas de matemática. Diante da resolução acima, uma aluna assim se manifestou na sala: "Olha como é importante a álgebra, nós fizemos um monte de conta que não era necessário”.

Essa mesma tarefa foi aplicada pela Luci Mara numa turma de $1^{a}$ série do ensino médio e as estratégias que os alunos utilizaram foram praticamente as mesmas dos alunos de $7^{\text {a }}$ série. Essa questão foi discutida no GRUCOGEO e houve o entendimento de que, para os alunos de $7^{\text {a }}$ série, não havia a nossa expectativa de que conseguiriam generalizar via equação de $2^{\circ}$ grau e analisar os intervalos da inequação gerados pelo problema:

$\mathrm{A}<\mathrm{P}$

$\ell^{2}<4 \boldsymbol{l}$

$\boldsymbol{\ell}^{2}-4 \ell<0$ (A análise das soluções dessa inequação permite concluir que, no intervalo de 0 a 4 , o perímetro é maior que a área; no intervalo superior a 4 , o perímetro é menor que a área).

No entanto, essa estratégia já é esperada de uma turma de $1^{\text {a }}$ série do ensino médio, mesmo porque, via de regra, o conteúdo de matemática dessa série inicia-se pelo estudo de intervalos e funções. Essa 
discussão provocou a seguinte reflexão de Carina - a autora da tarefa: "Pode ser que isso aconteça, pois a geometria e álgebra 'não são dadas' ao mesmo tempo; então a geometria se resolve por geometria e a álgebra por álgebra". Trata-se da fragmentação que vem marcando o ensino da matemática e que não leva em consideração que "a aprendizagem é, em grande parte, uma questão de estabelecer relações, ver as mesmas coisas de outros ângulos ou noutros contextos" (Abrantes, Serrazina \& Oliveira, 1999, p. 13).

\section{Refletindo com a experiência da professora Luci Mara}

A experiência vivenciada por Luci Mara, quando socializada e discutida no GRUCOGEO, nos propiciou reflexões de, pelo menos, três dimensões: (1) possibilidades e limites do uso de material didático no ensino de geometria; (2) possibilidades de generalização, tornando uma tarefa investigativa; (3) valorização das diferentes estratégias e argumentações em sala de aula.

Quanto ao uso de material didático no ensino de geometria, notamos a freqüência com que muitos alunos utilizaram o recurso do papel quadriculado como um suporte para a visualização e realização da tarefa proposta. Sem dúvida, esse uso revelou o quanto os alunos haviam se apropriado do conceito de área, visto que em momento algum o confundiram com o conceito de perímetro, aplicando-o adequadamente a novas situações. No entanto, se o quadriculado, por um lado, favoreceu a visualização, de outro, foi um limitador para a atribuição de valores não-naturais para a medida do lado do quadrado. Em todos os grupos, as conjecturas postas envolveram apenas números naturais. Nesse sentido, Pais (2000, p. 14), ao analisar o significado do uso de recursos didáticos no ensino da geometria, afirma:

O uso de materiais didáticos no ensino da geometria deve ser sempre acompanhado de uma reflexão pedagógica para que, evitando os riscos de permanência em um realismo ingênuo ou de um empirismo, contribua na construção do aspecto racional. Uma compreensão inicial pode induzir um aparente dualismo entre as condiçôes concretas e particulares dos recursos didáticos em oposição às condiçôes abstratas e gerais das noçôes geométricas. Mas esta dualidade não deve ser vista como pólos isolados do processo de construção conceitual, deve ser superada pela busca de um racionalismo 
aberto, dialogado e dialetizado. Em suma, devemos sempre estimular um constante vínculo entre a manipulação de materiais e situações significativas para o aluno.

$\mathrm{O}$ autor entende que o ensino da geometria vem se pautando no dualismo entre racionalismo e empirismo e que, muitas vezes, o uso de recursos didáticos restringe-se a uma visão empírica, desconsiderando o significado dos conceitos geométricos. Para a superação dessa visão, a prática pedagógica em geometria deveria contemplar as três dimensóes do conhecimento geométrico: representações por modelo, por desenho e imagem mental.

$\mathrm{Na}$ experiência aqui apresentada, entendemos que o objetivo da tarefa era analisar as conjecturas e estratégias de resolução e validação pelos alunos. No entanto, ela nos dá indícios de que uma etapa posterior do trabalho poderia ser a ampliação das idéias dos alunos, propondo questões que os levassem a utilizar valores não-naturais, inclusive compreendidos entre 0 e 1 . Essas questôes emergiram somente no momento da socialização da experiência no GUCOGEO.

Mesmo com a generalização apresentada pelo último grupo - objeto de nossa análise -, essa questão do lado não-natural evidenciou-se na discussão em sala de aula. A generalização do grupo mascara a possibilidade de a medida do lado não ser natural. No entanto, tal generalização nos possibilita considerar que essa tarefa se tornou investigativa. Dependendo da série e do grupo, as estratégias de resolução e de validação de uma conjectura poderão ou não ser ampliadas. As discussóes geradas no GUCOGEO foram possíveis em razão do envolvimento de seus participantes na aplicação e análise da tarefa, do domínio do conhecimento matemático e do próprio ambiente de compartilhamento existente no grupo. Nesse sentido, reforçamos a convicção de que não há como estabelecer, a priori, que uma tarefa é investigativa. Depende do grupo, do contexto e até mesmo do sujeito, como afirmou Luci Mara ao final de sua apresentação no GUCOGEO, quando indagada se ela considerava que essa tarefa tinha sido investigativa: "para o Rô foi, pois ele generalizou".

Entendemos, ainda, que, mesmo que uma tarefa não se torne investigativa, a dinâmica adotada para a sua realização (trabalho em pequenos grupos, registro das estratégias e socialização oral para a classe toda) cria um ambiente de comunicação de idéias matemáticas propício 
à produção de novos conhecimentos pelos alunos e implica desafios para o professor. Como afirma Santos (2005, p. 123):

O fato de que uma idéia matemática pode admitir diferentes formas de expressão e uma expressão pode representar diferentes idéias e contextos matemáticos implica desafios interessantes a serem enfrentados pelo professor, pois se trata de uma compreensão que o obriga a sair da cômoda posição de atribuir a cada símbolo ou expressão matemática um significado único e, reciprocamente, a cada idéia uma única forma de representação.

A análise dessa experiência nos revelou a importância de uma prática pedagógica pautada na valorização dos saberes dos alunos que são explicitados quando estes têm voz e são ouvidos. A dinâmica adotada por Luci Mara, ao propor que os grupos fizessem seu registro para ser socializado no retroprojetor, valorizou as diferentes estratégias utilizadas e os processos de argumentação e validação, possibilitando ainda a ampliação de idéias, quando uma das alunas destacou o valor da estratégia de Rô com a utilização da álgebra. Essa dinâmica cria uma nova concepção de cultura de aula de matemática. Como afirmam Abrantes, Serrazina e Oliveira (1999, p. 14): "Se a 'norma' é valorizar o envolvimento em processos de pensamento, assim como o raciocínio e argumentação lógica, pode criar-se uma cultura da aula de matemática muito diferente daquela que valoriza as respostas rápidas e certas".

Possibilidades para a sala de aula

As experiências que temos vivenciado no GUCOGEO em relação ao ensino de geometria na educação básica vêm apontando que as tarefas exploratório-investigativas possibilitam uma ruptura com o currículo linear, segundo o qual, para se ensinar um determinado conteúdo, exige-se um conhecimento prévio. Evidentemente, algum conhecimento prévio é necessário ser mobilizado para o levantamento de conjecturas diante de uma nova tarefa, mas os caminhos de resolução possibilitam a mobilização de outros conhecimentos de que o aluno já dispõe, ou a produção de novos conhecimentos.

As experiências com essa modalidade de tarefa vêm revelando que os alunos se envolvem em sua realização, pois sempre há a garantia de 
uma resposta possível - aquela que, no momento, o aluno e/ou o grupo conseguem elaborar. Isso, sem dúvida, representa, do nosso ponto de vista, a mudança da cultura de aula de matemática.

No caso da geometria, essas tarefas revelam-se ricas do ponto de vista da não-fragmentação do conhecimento matemático e de articulação de diferentes recursos didáticos, levantamento de conjecturas, estratégias de resolução e valorização da comunicação de idéias matemáticas.

Embora exista um número incipiente de publicações nacionais relativas a essa modalidade de tarefas, entendemos que elas possam ser elaboradas a partir até mesmo de um exercício presente em um livro didático. Basta que sejam elaboradas perguntas ("e se...") que provoquem dúvidas e gerem a necessidade de levantar conjecturas, buscar estratégias e analisar possibilidades para respondê-las.

Recebido em dezembro de 2007 e aprovado em março de 2008

\section{Referências}

ABRANTES, P. Investigações em geometria na sala de aula. In: ABRANTES, P. et al. (Org.). Investigaçóes matemáticas na aula e no currículo. Lisboa: APM, 1999. p. 153-167.

ABRANTES, P.; SERRAZINA, L.; OLIVEIRA, I. A matemática na educação básica. Lisboa: Ministério da Educação; Departamento da Educação Básica, 1999.

ANDRADE, J.A.A. $O$ ensino de geometria: uma análise das atuais tendências, tomando como referência as publicações nos Anais dos ENEMs. 2004. 249p. Dissertação (Mestrado em Educação) - Programa de Estudos Pós-Graduados em Educação, Universidade São Francisco, Itatiba (SP).

ANDRADE, J.A.A.; NACARATO, A.M. Tendências didático-pedagógicas no ensino de geometria: um olhar sobre os trabalhos apresentados nos ENEMs. Educação Matemática em Revista, Recife, v. 11, n. 17, p. 61-70, dez. 2004.

FERNANDES, D.; FONSECA, L. Argumentação e demonstração no contexto da formação inicial de professores. In: BorralHo, A.; 
Monteiro, C.; Espadeiro, R. A matemática na formação do professor. Évora: Sociedade Portuguesa de Ciências da Educação, 2004. p. 249-275.

GARNICA, A.V.M. As demonstrações em educação matemática: um ensaio. Bolema, Rio Claro, v. 15, n. 18, p. 91-99, 2002.

NACARATO, A.M. et al. Compartilhando saberes: professores e futuros professores em um grupo de trabalho colaborativo. In: CONGRESSO IBERO-AMERICANO DE EDUCAÇÃO MATEMATICA, 5., 2005, Porto. (CD-ROM)

PAIS, L.C. Uma análise do significado da utilização de recursos didáticos no ensino da geometria. 2000. Disponível em: <www.anped.org.br/23/ textos/1919t.pdf>

PONTE, J.P. Investigar, ensinar e aprender. In: ACTAS do PROFMAT. Lisboa: APM, 2003. p. 25-39. (CD-ROM)

PONTE, J.P.; BROCARDO, J.; OLIVEIRA, H. Investigações matemáticas na sala de aula. Belo Horizonte: Autêntica, 2003. 151p.

SANTOS, V.M. Linguagens e comunicação na aula de matemática. In: Nacarato, A.M.; Lopes, C.E. Escritas e leituras na Educação Matemática. Belo Horizonte: Autêntica, 2005. p. 117-125.

SMOLE, K.S. Textos em matemática: por que não? In: Smole, K.S., Diniz, M.I. (Org.). Ler, escrever e resolver problemas: habilidades básicas para aprender matemática. Porto Alegre: ARTMED, 2001. p. 29-68. 